\title{
What do mobile AR game players complain about?: A qualitative analysis of mobile AR game reviews
}

\author{
Misbahu S. Zubair \\ School of Psychology and Computer Science, University of Central Lancashire \\ Preston, United Kingdom \\ mszubair@uclan.ac.uk
}

\begin{abstract}
Augmented Reality (AR) combines real and virtual objects, provides opportunities for real-time interaction and provides accurate registration of 3D virtual and real objects. Mobile AR creates unique opportunities for gameplay unrestricted by the screen size of mobile devices with interactions possible between players, game objects and the real world. Since the launch of Pokémon Go in 2016, AR gaming has gone mainstream, several commercial mobile AR games have been launched, and researchers have conducted several studies on the motivations, intentions, and experiences associated with playing AR games. However, most studies in this area have focused on Pokémon Go, and have not included issues reported by players. This paper presents a study conducted with the aim of understanding issues, specifically those associated with the use of $A R$ in games, that mobile $A R$ game players face. User reviews for 10 popular commercial mobile AR games that utilise AR in all significant gameplay activities were gathered and analysed using Thematic Analysis to identify 11 themes of issues. This study adds to the body of knowledge and understanding of issues facing mobile AR game players and includes commercial mobile AR games other than Pokémon Go in the research on AR games.
\end{abstract}

Mobile Games. Augmented Reality. User Reviews. Qualitative Analysis. Thematic Analysis.

\section{INTRODUCTION}

Augmented Reality (AR) combines real and virtual objects, provides opportunities for real-time interaction and provides accurate registration of 3D virtual and real objects (Azuma, 1997). It can be utilised to enhance the user's perception of the real world and help in performing real and serious tasks, as well as to create unique, interactive and immersive experiences such as games. AR depends on capable devices with required displays, processors, input and tracking devices (Kesim \& Ozarslan, 2012). Headsets/Head-Mounted Displays (HMD) (e.g. Microsoft's HoloLens 2) that independently meet these requirements currently exist; however, there are some HMDs that require the processing abilities of mobile phones and external input devices, these are considered cheaper alternatives to stand alone AR HMDs. Most modern mobile devices themselves are AR capable devices, and can be used without HMDs for mobile AR experiences..

Mobile AR frees games from the limits of the screen size of mobile devices and allows players to interact with the world (objects and locations) around them, thereby providing unique opportunities for "borderless" gaming anywhere anytime (Wetzel et al., 2011). Mobile AR games can be independent of the player's location, placing content locally to the player e.g. using a Marker to position and track the AR scene, although Markerless AR experiences are now very common (Oufqir et al., 2020). They can also be loosely coupled to certain locations i.e. played at different locations; or contextual i.e. strongly tied to the area they are played in (Wetzel et al., 2011).

Although mobile AR games existed before the launch of Pokémon Go, It took the release of the game in 2016 for most mainstream consumers to be introduced to the concept of $A R$ and AR mobile games (Laine, 2018). Pokémon Go can be considered as a contextual, location-based, free-toplay mobile game created by Niantic Inc based on a Japanese media franchise. The game uses AR to allow players playing on their mobile devices to capture virtual pocket monsters that are augmented to their real environment. The nature of the environment determines the nature of the Pokémon found in the surroundings. Within two months of its release, it was downloaded more than 500 million times and won multiple game awards the same 
year (Hamari et al., 2019). An update by Niantic in December 2016 announced that players of the game have caught a combined total of more than 88 billion Pokémon, while collectively walking more than 8.7 billion kilometres (Niantic - The Pokémon GO Team, 2016).

What followed the Pokémon Go hype was an increase in the demand for AR experiences as AR mobile consumers began increasing. According to AR Insider, the number of active mobile AR users worldwide as of 2020 was 598 million, and this number is expected to grow to 1.73 billion by 2024 (AR Insider, 2021). The increased demand for AR experiences on mobile led to the launch of several other commercial mobile AR games, including those also based on existing franchises e.g. Harry Potter: Wizards Unite, Angry Birds AR: Isle of Pigs and Minecraft Earth.

Another consequence of the Pokémon Go hype is the effect it had on research on AR games and AR game players. Although research studies on AR mobile games were being conducted long before Pokémon Go, they were mostly focused on educational games (Furió et al., 2015; Zarzuela et al., 2013), and the potentials, opportunities and applications of AR for other serious (Angelopoulou et al., 2012; Botella et al., 2011). The launch and popularity of Pokémon Go inspired new research studies with aims including identifying the motivation for playing AR games (Alha et al., 2019; Bueno et al., 2020; Zsila et al., 2018), the attitudes and intentions of mobile AR game players (Hsiao et al., 2019; Rauschnabel et al., 2017), and player experiences and engagement in AR games (Pyae et al., 2017; Pyae \& Potter, 2016). However, little research on the issues faced and reported by players of mobile AR games has been conducted both before and after the launch of Pokémon Go. There is also a heavy focus on Pokémon Go when researching commercial mobile AR games. While this is not surprising due to its unparalleled popularity and impact, the one-sided research effort has led to the exclusion of other mobile AR games from this research.

Additionally, studies focused on Pokémon Go have limitations that could impact the generalizability of their findings. Respondents in these studies may have been affected by the Pokémon Go hype either negatively or positively; factors found to affect Pokémon Go players' behaviour, experience and opinions such as nostalgia, recreation and outdoor activities (Rauschnabel et al., 2017; Zsila et al., 2018) may not be present in other mobile $A R$ games; finally, AR is only utilised in Pokémon Go for capturing pocket monsters and not in other significant gameplay activities, in fact, the game can be played without AR all together.

This study aims to understand issues, specifically those associated with the use of AR in games, that mobile AR game players face. This will be done by analysing the user reviews for popular commercial mobile AR games that utilise AR in all significant gameplay activities. In doing so, this study takes advantage of rich publicly available data provided by a large and diverse group of mobile AR game players that provides insights into their experiences.

The findings of this study add to the body of knowledge on the understanding of issues facing mobile AR game players and include commercial mobile AR games other than Pokémon Go and their players in this area of research.

\section{RELATED WORK}

\subsection{Mobile AR Games}

Early research on mobile AR games mostly focused on the applications and benefits of $A R$ in mobile games, especially for educational serious purposes. Some of the applications that have been studied include subject-specific learning (Furió et al., 2015; Zarzuela et al., 2013), improving social interaction and collaboration (Koceski \& Koceska, 2011), recycling (Juan $M$ et al., 2011), tourism (Angelopoulou et al., 2012; Etxeberria et al., 2012; Rodrigo et al., 2015), rehabilitation and therapy (Botella et al., 2011; Garcia \& Navarro, 2014).

Several studies on mobile AR games' player experiences (Pyae et al., 2017; Pyae \& Potter, 2016), including identifying the motivation for playing AR games (Alha et al., 2019; Bueno et al., 2020; Zsila et al., 2018), the attitudes and intentions of mobile AR game players (Hsiao et al., 2019; Rauschnabel et al., 2017), have been conducted since the launch and success of Pokemon Go brought mobile AR games out of research labs into mainstream usage. However, there is still little research involving experiences of players of other commercial mobile AR games, and on challenges and issues faced by players of mobile AR games.

\subsection{Analysis of User Review}

Application marketplaces such as Google's Play Store, Apple's App Store and Steam allow users to leave reviews and ratings for applications. Ratings allow users to assign a quantitative value based on their satisfaction with the app e.g. using a 5-star rating system. Reviews, on the other hand, are qualitative and serve several purposes such as giving feedback to developers, informing other users or potential users, reporting bugs, and even requesting new features (Di Sorbo et al., 2017; Maalej \& Nabil, 2015). While a review is not required to rate an app, a rating is required to review an app in most application marketplaces (Mojica Ruiz et al., 2016). 
Reviews are now considered rich sources of crowdsourced information; they have been collected and analysed in research studies to extract information that can aid in improving applications (Panichella et al., 2015), and in understanding user experiences and issues (Khalid et al., 2015).

The application(s) whose reviews are analysed depend on the aim of the study and can be selected based on popularity rankings (Khalid et al., 2015), searching the marketplace with relevant keywords based on the research study (Frie et al., 2017; Tan et al., 2020), utilising a precompiled list of relevant applications (Saoane Thach \& Phuong Nam Phan, 2019; Thach, 2018), utilising category created by the market place with relevant applications (Fagernäs et al., 2021), randomly (lacob \& Harrison, 2013) etc. The reviews for the selected application(s) are then gathered usually using a scraping script. Existing studies have used review sample sizes ranging from hundreds (Faric et al., 2019) to millions (Hoon et al., 2012).

Statistical quantitative analysis and machine learning approaches are popular methods of analysing reviews due to the large number of reviews that are usually available for popular applications. These approaches have been successfully used to address several research objectives, for example, to identify: the relationship between aspects within reviews and ratings (Guzman \& Maalej, 2014; Huebner et al., 2018), reported bugs (Gao et al., 2018; Panichella et al., 2015), relationships between review length and rating (Vasa et al., 2012), review sentiments and the vocabulary used to express sentiment (Hoon et al., 2012), and retrieve feature requests (lacob \& Harrison, 2013).

However, not all research objectives can be addressed using quantitative methods. Studies aimed at understanding the context and not just identifying concepts such as experiences, opinions and issues and perceptions, take a qualitative approach to review analysis (Faric et al., 2019; Frie et al., 2017; Saoane Thach \& Phuong Nam Phan, 2019; Thach, 2018). Due to the potentially large number of reviews available, a sampling approach is usually needed to decide a subset from the complete set of reviews for qualitative analysis. Examples of such sampling approaches found in the literature include selecting the top 10 most recent reviews for each app (Faric et al., 2019) or taking reviews within a certain time range (Saoane Thach \& Phuong Nam Phan, 2019; Thach, 2018). This results in a more manageable sample size that can be manually analysed by researchers using, for example, thematic analysis (Faric et al., 2019; Frie et al., 2017; Tan et al., 2020; Thach, 2018).

\section{METHODOLOGY}

\subsection{Data Collection}

Ethical approval was sought and granted by the University of Central Lancashire's Ethics Review Panel before the start of data collection (SCIENCE $0117 \mathrm{CA})$. Data collection then began with identifying popular mobile AR games that utilise AR in all significant gameplay activities. This was done by searching Google Play Store apps using the search term "augmented reality game" searched in March 2021. The search was performed using a Google Chrome incognito browser window not connected to a Google account to avoid search results affected by an account's preferences. The search returned 250 results which were reviewed using a developed set of inclusion criteria to ensure AR games with a significant number of user downloads and reviews are selected for the study. The first 10 games that met these criteria were selected for the study. To meet the criteria, a game within the search result must:

(i) have been downloaded at least 100,000 times,

(ii) have been reviewed at least 1000 times,

(iii) utilise $A R$ (Azuma, 1997) in all its main gameplay activities.

Criteria 'i' and 'ii' were checked by reviewing a game's information on its Play Store page. Games that met both criteria were downloaded and played to test if they met criteria 'iii'. Review articles, review and gameplay walkthrough videos were used to check for criteria 'iii' in games that required equipment e.g. markers and HMDs to be used with a mobile device. By following these inclusion criteria, games that only use AR in a single mode or as an additional feature, only overlay images on camera view, have a low number of downloads or user reviews, were all excluded. The games selected and their descriptions, in brief, are presented in Table 1.

The complete set of reviews for the 10 selected games were downloaded using a python review scrapping script and saved as excel spreadsheets. To ensure the anonymity of reviewers, the scrapping script was customised to save only the review text, the star rating, and the thumbs-up count for each review and discard identifying information such as username and profile picture. In total, 36,231 reviews were saved.

Table 1: Selected games and their descriptions in brief.

\begin{tabular}{|c|l|l|}
\hline Game & \multicolumn{1}{|c|}{ Title } & \multicolumn{1}{c|}{ Description } \\
\hline \multirow{3}{*}{ G1 } & $\begin{array}{l}\text { Angry Birds } \\
\text { AR: Isle of } \\
\text { Pigs }\end{array}$ & $\begin{array}{l}\text { AR instalment in the Angry } \\
\text { Birds franchise. Players } \\
\text { destroy pigs and their } \\
\text { structures using slingshots. }\end{array}$ \\
\hline
\end{tabular}




\begin{tabular}{|c|c|c|}
\hline & & $\begin{array}{l}\text { They can walk around } \\
\text { structures to find weak } \\
\text { elements, identify different } \\
\text { angles for the best accuracy. } \\
\text { Markerless and requires no } \\
\text { extra equipment. }\end{array}$ \\
\hline G2 & $\begin{array}{l}\text { Five Nights at } \\
\text { Freddy's AR: } \\
\text { Special } \\
\text { Delivery }\end{array}$ & $\begin{array}{l}\text { AR instalment in the Five } \\
\text { Nights at Freddy's franchise. } \\
\text { Players turn around in their } \\
\text { real environment to find and } \\
\text { confront malfunctioning } \\
\text { animatronics to survive these } \\
\text { horrors come to life. } \\
\text { Markerless and requires no } \\
\text { extra equipment. }\end{array}$ \\
\hline G3 & $\begin{array}{l}\text { Ghosts 'n } \\
\text { Guns AR }\end{array}$ & $\begin{array}{l}\text { The player shoots at ghosts } \\
\text { that emerge from a portal } \\
\text { placed in the player's } \\
\text { environment. } \\
\text { Markerless and requires no } \\
\text { extra equipment. }\end{array}$ \\
\hline G4 & $\begin{array}{l}\text { Hero Vision } \\
\text { Iron Man AR } \\
\text { Experience }\end{array}$ & $\begin{array}{l}\text { The player plays as iron Man } \\
\text { and shoots at enemies. } \\
\text { Marker-based; requires the } \\
\text { purchase of a set that } \\
\text { includes goggles to hold the } \\
\text { player's device, an Iron Man } \\
\text { mask to hold the goggles } \\
\text { over the player's face, a set } \\
\text { of markers, and scannable } \\
\text { infinity stones. }\end{array}$ \\
\hline G5 & Kazooloo AR & $\begin{array}{l}\text { The player fights enemies } \\
\text { emerging from the Kazoolo } \\
\text { game board } \\
\text { Marker-based; requires the } \\
\text { purchase of a Kazoolo game } \\
\text { board. }\end{array}$ \\
\hline G6 & Knightfall $A R$ & $\begin{array}{l}\text { Strategy game where the } \\
\text { player defends a castle } \\
\text { against an invasion. } \\
\text { Markerless and requires no } \\
\text { extra equipment. }\end{array}$ \\
\hline G7 & $\begin{array}{l}\text { Minecraft } \\
\text { Earth (Early } \\
\text { Access) }\end{array}$ & $\begin{array}{l}\text { AR instalment in the } \\
\text { Minecraft franchise. The } \\
\text { Player explores, collect } \\
\text { resources, builds and } \\
\text { survives. } \\
\text { Markerless and requires no } \\
\text { extra equipment. }\end{array}$ \\
\hline G8 & $\begin{array}{l}\text { Pulimurugan } \\
\text { AR Game }\end{array}$ & $\begin{array}{l}\text { Based on the movie titled } \\
\text { 'Pulimurugan'. The player } \\
\text { fights a tiger. } \\
\text { Marker-based; requires a } 10 \\
\text { Rupee Indian currency note, } \\
\text { preferably ones released in } \\
\text { years } 2014,2015,2016\end{array}$ \\
\hline G9 & $\begin{array}{l}\text { Star Wars }{ }^{T M}: \\
\text { Jedi } \\
\text { Challenges }\end{array}$ & $\begin{array}{l}\text { AR instalment in the Star } \\
\text { Wars game franchise. The } \\
\text { player plays as a Jedi and }\end{array}$ \\
\hline
\end{tabular}

\begin{tabular}{|l|l|l|}
\hline \multirow{1}{*}{} & & $\begin{array}{l}\text { can take on several } \\
\text { challenges including } \\
\text { lightsaber battles. }\end{array}$ \\
& $\begin{array}{l}\text { Marker-based; requires the } \\
\text { Star Wars: Jedi Challenges } \\
\text { gear (Lenovo Mirage AR } \\
\text { headset, lightsaber } \\
\text { controller, and tracking } \\
\text { beacon) }\end{array}$ \\
\hline \multirow{6}{*}{ G10 } & $\begin{array}{l}\text { The player plays as a } \\
\text { shooter on a rescue chopper } \\
\text { with the objective of stopping } \\
\text { zombies from reaching a } \\
\text { survivor base. } \\
\text { Reality }\end{array}$ & $\begin{array}{l}\text { Marker-based; requires a } \\
\text { marker that can be accessed } \\
\text { online and printed. }\end{array}$ \\
\hline
\end{tabular}

\subsection{Sampling Reviews}

Since the aim of the study is to understand issues that reviewers complained about, a qualitative approach to data analysis is more appropriate. Therefore a sampling approach had to be developed, as analysing all 36,231 reviews qualitatively will be almost impossible. Similar studies have analysed only the most recent reviews (Faric et al., 2019), or reviews within a particular period (Saoane Thach \& Phuong Nam Phan, 2019; Thach, 2018). However, these approaches do not address the sampling problem for app store mining (Martin et al., 2015) as they may miss out on reviews with relevant information from excluded periods.

The approach taken in this study ensures the most relevant reviews are included in the data to be analysed by selecting reviews based on their 'helpfulness' rather than their creation date. Review 'helpfulness' is used to measure the "utility or diagnosticity" of reviews as voted by users (Karimi \& Wang, 2017). Play Store records the helpfulness of reviews as a thumbs-up count i.e. positive difference between thumbs-up and thumbs-down received by a review. To ensure that helpful reviews are chosen across all possible ratings, the top 10 most helpful reviews for each rating were chosen for each selected game i.e. 10 most helpful reviews with 5 stars, 10 most helpful reviews with 4 stars, 10 most helpful reviews with 3 stars, 10 most helpful reviews with 2 stars and 10 most helpful reviews with 1 star. In cases where multiple reviews have the same helpfulness i.e. thumbs-up count, the most recent review is prioritised for selection. The final sample was made up of 500 reviews, made up of 50 reviews per game. This approach was taken to ensure the selection of a sample that includes the most relevant reviews across all rating groups across all selected games. 


\subsection{Data Analysis}

Thematic analysis, "a method for identifying, analysing and reporting patterns (themes) within data" (Braun \& Clarke, 2006) was used to identify and analyse patterns in user complaints within reviews as used in similar studies (Faric et al., 2019; Frie et al., 2017; Tan et al., 2020; Thach, 2018). Content Analysis, which is used to explore textual data to determine trends and patterns of words used, their frequency and relationships (Vaismoradi et al., 2013) was also considered. Thematic Analysis was chosen since the aim of this study is not to prioritise or count issues, but to identify them and understand the context in which they occur.

The phases provided by Braun \& Clarke (2012) were followed in ensuring the flexibility of the method is not abused and a systemic analysis of data was conducted. Data analysis started with the researcher reading all sampled reviews to gain familiarity, the researcher took notes and made comments about reviews found to be interesting and their associated games. Then the researcher coded the reviews using an inductive approach i.e. with an open mind labelled interesting reviews or segments of reviews with labels describing their content (Braun \& Clarke, 2012). On completing coding, codes were reviewed to identify overlaps and patterns to construct themes. To ensure that the themes constructed truly reflect the content of the complete data set, the complete set of all 36,231 reviews was searched using keywords and key phrases from coded reviews and themes to identify the existence of reviews that could validate and strengthen them. The keywords and search phrases used include verbatim words found to be common amongst coded data and words assigned by the researcher (e.g. synonyms of verbatim words) to improve the chances of finding relevant reviews. For example, the verbatim search keywords used for the Dizziness and Location themes include "dizzy" and "outside" respectively, while the researcher assigned keywords include "sick" and "outdoor" respectively. This process led to the validation of existing themes (e.g. Location, Dizziness), the extension of other themes (e.g. Extra Equipment), the construction of new themes from existing codes previously categorised as miscellaneous (e.g. Accessibility, Device Utilisation) and the construction of an entirely new theme (Gameplay). A complete list of all themes their description, in brief, is provided in Table 2. This validation process also served to reduce the impact of a possible sampling bias (Martin et al., 2015). Finally, the coded reviews or review segments for each theme were analysed to identify those that provide an accurate narrative of what is embedded in the complete data set, these were selected and are presented with each theme in the section that follows.

Table 2: Constructed themes and their descriptions in brief.

\begin{tabular}{|l|l|}
\hline \multicolumn{1}{|c|}{ Theme } & \multicolumn{1}{c|}{ Description } \\
\hline Guidance & $\begin{array}{l}\text { Lack of guidance on setting up } \\
\text { and playing games. }\end{array}$ \\
\hline Dizziness & $\begin{array}{l}\text { Feeling dizzy as a result of } \\
\text { moving around while playing. }\end{array}$ \\
\hline Location & $\begin{array}{l}\text { Having to play outside or in } \\
\text { large spaces only. }\end{array}$ \\
\hline Accessibility & $\begin{array}{l}\text { Facing accessibility barriers to } \\
\text { gameplay. }\end{array}$ \\
\hline Gameplay & $\begin{array}{l}\text { Poor utilisation of AR in } \\
\text { improving gameplay. }\end{array}$ \\
\hline $\begin{array}{l}\text { Plane } \\
\text { detection }\end{array}$ & $\begin{array}{l}\text { Difficulty detecting planes to } \\
\text { place the game scene. }\end{array}$ \\
\hline Tracking & $\begin{array}{l}\text { Difficulty tracking the scene or } \\
\text { game objects. }\end{array}$ \\
\hline Battery drain & $\begin{array}{l}\text { Battery consumption becomes } \\
\text { high when playing the game. }\end{array}$ \\
\hline Overheating & $\begin{array}{l}\text { The device becomes very hot } \\
\text { when playing the game. }\end{array}$ \\
\hline $\begin{array}{l}\text { Device } \\
\text { utilisation }\end{array}$ & $\begin{array}{l}\text { Poor utilisation of the player's } \\
\text { device and its capabilities. }\end{array}$ \\
\hline $\begin{array}{l}\text { Extra } \\
\text { equipment }\end{array}$ & $\begin{array}{l}\text { Issues associated with the need } \\
\text { for such equipment, cost, } \\
\text { availability, compatibility with } \\
\text { devices and reusability }\end{array}$ \\
\hline
\end{tabular}

\section{FINDINGS}

The themes constructed through thematic analysis are provided in this section. Each theme is briefly discussed and examples of coded reviews or review segments are also provided. It should be noted that quoted reviews have been minimally amended to correct spelling and grammar errors, remove emojis, and to preserve the anonymity of reviewers by removing sensitive information without changing their intent (Nicholas et al., 2017).

\subsection{Guidance}

Findings highlighted reviews expressing frustration over the complexity of setting up and playing some mobile AR games with no guidance:

If only there were more instructions on what size of surface to use, what kind of lighting is needed, or if the playfield is scalable to what is available. (Game: G6)

"What is this game? There is absolutely no instruction or tutorial, even in the beginning. I have absolutely no idea what I am supposed to do. (Game: G7) 


\subsection{Dizziness}

Some AR games demand a certain degree of physicality to play, this is usually in the form of utilising a players movement in their physical environment as a mechanic in the game. Some reviewers of these games reported a feeling of dizziness as a result of moving around while playing:

The only bad thing is that for players like me who get dizzy easily, if we play for more than 10 minutes we get really dizzy from looking and spinning around. Other than that, really awesome game. really recommend trying it out. (Game: G2)

Makes me dizzy but it's still fun as long as you ignore annoying stuff like in-app purchases. (Game: G7)

\subsection{Location}

Some of the games reviewed require players to be outdoors to complete part of the game loop. However, playing outdoors is not always ideal as shown by the reviews below:

So far it has been alright. However, it uses so much battery and data that it is impractical to play outside without using battery packs. And having a really large data package. We only played a bit outside and it jumped my phone data a gig. Very reluctant to try again but we will. (Game: G7)

Also, It's too cold outside to play, who's idea was it to launch at the start of winter? l'll try again in spring when I can play it (Game: G7)

Another issue found to be reported by reviewers associated with location is the size requirements that need to be met for some games to be playable:

A little confusing at first, but really fun. It's hard to play in small spaces, you have to be in an open area, standing. (Game: G2)

It is very fun when it works. The adventures are too big to play comfortably anywhere but an empty field and the motion tracking is terrible and the adventures end up sliding around constantly. (Game: G7)

\subsection{Accessibility}

AR games may utilise player movement as a mechanic, this could lead to accessibility issues for players with mobility issues as revealed by a review shown below:

When I got this there was no indication that you're expected to constantly move around the piece of cardboard you place on the floor. So, if you're in a wheelchair or have problems walking simply forget this thing. (Game: G5)
In addition to player movement mechanics, other features such as flashing lights and images, especially in games that require headgear, can also lead to accessibility issues to those that are sensitive:
If you are epileptic or sensitive to flashing lights this game is NOT for you. I am dizzy after less than a minute of trying to play this game. When you click to collect items the screen flashes a lot very bright and very quickly with animations. I am not able to play this game at all. Please be careful. (Game: G7)

Finally, some reviews complained about the visibility of objects in the game complaints caused by the scale of the scenes:

There are lots of kinks to work out such as the flat surface since it's hard for my phone to find. And when one is found, I sometimes find it hard to see on my phone when it's too far. (Game: G1)

It's hard to see the enemy, everything is so small. (Game: G6)

\subsection{Gameplay}

Some reviewers found some of the games analysed lacking in terms of gameplay, despite their use of AR. This can be seen in the following reviews:

Awkward and confusing. An AR haunted house idea is pretty cool. But this doesn't go beyond turning around. (Game: G2)

Nice innovation, but after prolonged use it gets boring. There's not much to do other than shoot. (Game: G3)

The graphics are nice but the gameplay is booooooring. (Game: G8)

\subsection{Plane detection}

Some reviewers complained about being unable to detect a surface to "place" their games, for example:

Can't even start a game because the camera cannot detect a flat surface. When it does find a surface, the stage jumps randomly off-screen, then crashes most of the time. (Game: G1)

Can't even get it to recognize any of the flat surfaces in my room. Floor, table, counter, bed, nothing. (Game: G6)

\subsection{Tracking}

There were also complaints about tracking the scene while playing the game. This was more common in games that required player movement. For example: 
When I turn to shock the animatronic, It constantly stays to the left of my screen no matter where I'm facing, making it impossible to hit. I just can't play this. (Game: G2)

Really well made AR game for android, though it gets out of position when you move too fast. But the experience is really nice... (Game: G3)

It's a great idea. However, the game freezes to recalibrate when you move too close, too far, too fast, or away from the page a bit. (Game: G10)

\subsection{Battery drain}

Several reviewers reported having the batteries of their devices drained as a result of playing the reviewed AR games, for example:

\footnotetext{
I liked the game, it was fun, although the battery drain is high and AR would stop working every now and then so the ghosts would hit me and I couldn't aim at them. (Game: G3)

Cool game, but it drains a lot of battery. (Game: G10)
}

\subsection{Overheating}

There were also complaints about devices overheating during gameplay. Reviewers reported having to stop playing after a little while due to this issue and in some cases becoming concerned, for example:

\begin{abstract}
Makes my device hot enough to slowly cook an egg. (Game: G6)

I wanted to give the game a try, but my device got that hot I felt it was going to explode or something. It looks like it might be a good game but maybe it shouldn't run on mobile. I don't want to risk losing my phone. (Game: G9)
\end{abstract}

\subsection{Device utilisation}

There were complaints from users with devices that they considered "low-end" on the performance of games on those classes of devices, for example:

\footnotetext{
Nearly impossible to play on lower-end devices, haywires are pretty much instant death, camera tracking doesn't work properly...; if you have a compatible device lower than [device], DON'T BOTHER! (Game: G2)
}

There were also complaints from reviewers who own "high end" about issues they believed should not be occurring on devices with specs as good as theirs, for example:

The gameplay is very nice but the problem is when playing the game my mobile heats up. I tried other devices and noticed the same thing, they get overheated. Even when handling bigger applications my mobile didn't heat up this much.
So I hope you can resolve the problem in your next update (Game: G1)

The premise is really good and I've seen more than flattering gameplay but for some reason even though my phone is a [device] that should be more than enough for this game it crashes as soon as the presentation for Chica and Foxy in the opening and doesn't go any further. (Game: G2)

\subsection{Extra Equipment}

Games that require the use of extra equipment, including markers, received several complaints in their reviews associated with the following:

\subsubsection{Use}

Several reviewers complained about the need for equipment with attached costs in the games that required them, for example:

\section{CAN YOU MAKE THE APP TO USE GOOGLE CARDBOARD? It would be better if you do so. (Game: G4)}

Forces you to buy things and if you don't have them you can't play. Should be optional for you to have the toys. (Game: G5)

I rarely give 1 star but I'm disappointed that I need to buy expensive gear for this. It would be better if I could just Chromecast the game onto my tv and use my phone as a lightsabre. (Game: G9)

\subsubsection{Compatibility}

Complaints about compatibility issues were made by several reviewers who own extra equipment but were unable to use them with their devices, for example:

Won't connect with my phone, even though it's on the compatible list. I've uninstalled and reinstalled and it doesn't work. It's a waste of money. (Game: G9)

My phone isn't connecting to my lightsabre because it "isn't compatible" even though it fits in the headset and has Bluetooth capability. (Game: G9)

\subsubsection{Cost}

In addition to complaints on the requirement to use extra equipment, some reviewers complained about the associated cost implications, whilst still expressing their interest in the game. Examples are provided below:

This app is fantastic but the set is very expensive. (Game: G4)

The game is fun but $\$ 180$ is a very steep price to pay to play it. (Game: G9) 


\subsubsection{Availability}

In some cases, reviewers willing to purchase extra equipment were unable to do so due to lack of availability in certain regions and in online stores, for example:

I saw a review video on this and was impressed and enjoyed the demo version. Unfortunately, the boards were not readily available in Canada at that time. (Game: G5)

There were also complaints about the availability of markers that did not have to be purchased, for example:

Awesome game but make it compatible for new 10rs notes, it's hard to find 2016 edition 10rs notes. (Game: G8)

Link for the marker image does not work...it fails to download every time. (Game: G10)

\subsubsection{Reusability}

What else can my equipment be used for? This was a question that was found in several reviews associated with required extra equipment. Examples are shown in the reviews below:

It is an awesome game. First, I bought the board game and then downloaded the app. It is really awesome. But I want to ask one thing, do the board and the app become a waste if the game ends? (Game: G5)

This is an amazing game, I love it, my one problem is that I beat everything on it, and so now it just sits on the shelf collecting dust. (Game: G9)

\section{DISCUSSION}

This study analysed the reviews of 10 popular mobile AR games to understand the issues reviewers complained about.

Although mobile AR games are becoming more and more popular, AR is still somewhat novel to a lot of users and its interaction methods and practices are still evolving (Ghazwani \& Smith, 2020). This means that not all players will be able to intuitively set up and play mobile AR games, and several players may struggle to do so without clear and appropriate guidance and instructions. That is why guidelines for mobile AR games and applications have recommended providing help, documentation and training to uses (Tuli \& Mantri, 2020).

Several research studies on the popularity and motivations associated with Pokémon Go have identified outdoor play and exercise as important factors that affect the opinions of players e.g. Rauschnabel et al. (2017) and Zsila et al. (2018). However, findings from this study have shown that these factors may not be favoured by all players. In fact, some users prefer to play indoors for several reasons including weather conditions, access to $\mathrm{Wi}-\mathrm{Fi}$, access to a charging port and personal preference; and therefore do not prefer contextual mobile AR games or games that require a large space to play that may be difficult to find indoors. Additionally, although some reviewers enjoyed the exercise provided by AR games that require player movement, others preferred to use minimal physical effort in playing as proposed by Ko et al.'s (2013) usability principles for mobile AR applications, others still reported a feeling of dizziness as a result of moving around while playing. Dizziness has been observed in participants of studies on the use of AR applications, and although it has been found to occur more frequently in participants HMDs it is also experienced by participants using mobile devices (Moro et al., 2021).

Accessibility was also found to be impacted by the need to move around while playing excludes players with mobility issues. Other accessibility issues found by this study include the use of flashing lights and visibility issues that sometimes result from the low scaling of game scenes.

Although AR has the potential to allow for the creation of games with gameplay, it is sometimes used in games based on the assumption that it will automatically improve it and not because it adds nothing to the gameplay (Wetzel et al., 2011). Some reviewers felt the same way about their reviewed games, especially after playing for a while of getting used to the AR novelty of viewing 3D objects in their real environment.

It is safe to say that the most common complaints encountered were those associated with plane detection issues and tracking issues, which are challenging issues associated with $A R$ in general. Tracking issues, specifically, have been reported in other AR application domains by other researchers (Palmarini et al., 2018; Qian et al., 2019; Sanna \& Manuri, 2016). Based on the findings of this study, these issues made games "unplayable" either by preventing players from detecting a surface to set up the game scene or having tracking issues that affect the scene, game objects and players positioning and scale. Similarly, Mulloni et al. (2012) found tracking issues caused users to stop using AR browsers due to frustration. Player behaviours that can cause these issues as found by Radu et al. (2017) include: moving the camera so it is not able to view the marker(s), covering the device camera, and aiming too close or away from the marker (for marker-based AR). Another cause of these issues could be the lighting condition of the players environment or the texture of the plane (in the case of plane detection). 
Two other important technical issues were found in user reviews: overheating and battery drain. These have been previously identified as challenges facing the implementation of mobile AR (Chen et al., 2018). Some reviewers pointed the finger at poor optimisation of games, while others were not surprised by the occurrence of the issues given the nature of the processing required by AR games. Research has proved that AR games can cause overheating and battery drain in mobile devices dues to factors like camera usage (Kang et al., 2019) and the high processing demands (Qiao et al., 2019); this means that even well optimised mobile AR games could be facing these issues. This is unfortunately the state of the AR and mobile technology presently, and so high-end mobile devices are also likely to face such issues.

When it comes to mobile AR games that require the use of extra equipment including markers, this study found reviewers to complain about the need for the equipment. Availability, high cost, compatibility and the lack of reusability of the equipment. Several reviewers thought equipment that required purchase should be optional and that all mobile AR games should be playable with just a mobile device and nothing else required. While the cost of the extra equipment associated with the reviewed games is low compared to the cost of standalone AR devices such as Microsoft's HoloLens, it should be noted that the population of mobile game players is mostly made up of individuals that do not spend on games is significantly larger than that of those that do. A study by AppsFlyer (2016) found only $3.5 \%$ of gamers spend money in games and paid for games make up less than $38 \%$ of mobile revenue (Civelek et al., 2018). Therefore, it is not surprising that this group of users find the costs of the equipment high, were frustrated when their devices could not use the equipment and disliked the fact that the equipment have limited use.

For markers that are freely available to access, there were complaints about their availability, in one game (G10) most complaints were about a broken link, while in another (G8) complaints were about access since the marker is a currency available only in a single country. There were also availability complaints about other equipment due to lack of stock in certain countries and regions, or lack of stock altogether. Ensuring the availability of web links, the use of universally available markers and making games only available to regions where equipment can be accessed could be used to resolve these issues.

\subsection{Recommendations}

While some of the challenges identified by this study can only be resolved by advances in technology (both hardware and software) e.g. tracking, plane detection and battery drain, some challenges can be avoided or mitigated when designing mobile AR games with the present technology. Therefore, design recommendations for avoiding or mitigating some of the issues identified by this study are provided below:

- Provide clear guidance and instructions for setting up and playing the game. This should be presented in a way that is clear to all players, including those not familiar with AR games and AR technology in general.

- Include warnings in games with flashing lights and fast-moving images; also Include warnings of dizziness in games that require quick and frequent movement.

- Where possible, design breaks games that require movement, especially quick and frequent movement, to allow players to rest.

- Where possible, consider the player location's weather conditions when providing game objectives/missions in location-based mobile AR games.

- Where possible, design games to have, at least, levels or modes that are playable without the purchase and use of extra equipment.

\section{CONCLUSION}

This study collected and analysed reviews of popular mobile AR games on Google's Play Store with the aim of understanding issues associated with the use of $A R$ in games that users complain about. Each game's most helpful reviews across all ratings were analysed using thematic analysis to find themes that makeup patterns in user complaints, then the complete set of reviews were searched using relevant keywords from coded reviews to validate the themes constructed. This resulted in the construction of 11 themes of user complaints namely. While most of the issues identified and discussed in this study have been reported in $A R$ games and other $A R$ application domains, issues such as accessibility, device utilisation and those related to extra equipment have not been reported widely by other studies on mobile AR games. Given the challenges that come with the use of AR in mobile games, this study recommends that designers and developers only utilise AR if it improves the gameplay of a game and not just because of the novelty effect it will have on players.

A limitation of this study is that the analysis of reviews was conducted by a single researcher. This raises the question of coding reliability and highlights the impossibility of conducting checks such as inter-coder reliability checks. However, thematic analysis as described by (Braun \& Clarke, 
2012) can be performed by a single researcher and favours inductive flexible theme development through immersive and repeated engagement with the data over the agreement on codes between multiple researchers (Terry et al., 2017). The use of both sampled reviews and the complete set of reviews allowed this study to construct strong themes through immersive and repeated engagement with the data that identified both issues and their contexts; this would not have been entirely possible if only the sampled data was used.

Based on the lessons learnt from this study, it is recommended that approaches that allow the use of sampled data to ease qualitative analysis and also utilise the complete data set to identify missing information should be utilised in qualitative research of user reviews.

As future work, reviews from a larger set of games from both Google's Play Store and Apple's App store will be analysed both qualitatively, to understand reported issues, and quantitatively, to include all reviews in the analysis thus identifying finer aspects of mobile AR games that reviewers complain about.

\section{REFERENCES}

Alha, K., Koskinen, E., Paavilainen, J., \& Hamari, J. (2019). Why do people play location-based augmented reality games: A study on Pokémon GO. Computers in Human Behavior, 93, 114-122. https://doi.org/10.1016/j.chb.2018.12.008

Angelopoulou, A., Economou, D., Bouki, V., Psarrou, A., Jin, L., Pritchard, C., \& Kolyda, F. (2012). Mobile Augmented Reality for Cultural Heritage (pp. 15-22). https://doi.org/10.1007/978-3-642-30607-5_2

AppsFlyer. (2016). The State of In-App Spending: Global \& Regional Benchmarks, 2016.

AR Insider. (2021). How Big is the Mobile AR Market? https://arinsider.co/2021/02/23/howbig-is-the-mobile-ar-market-2/

Azuma, R. T. (1997). A Survey of Augmented Reality. Presence: Teleoperators and Virtual Environments, 6(4), 355-385. https://doi.org/10.1162/pres.1997.6.4.355

Botella, C., Breton-López, J., Quero, S., Baños, R. M., García-Palacios, A., Zaragoza, I., \& Alcaniz, M. (2011). Treating cockroach phobia using a serious game on a mobile phone and augmented reality exposure: A single case study. Computers in Human Behavior, 27(1), 217-227.

https://doi.org/10.1016/j.chb.2010.07.043

Braun, V., \& Clarke, V. (2006). Using thematic analysis in psychology. Qualitative Research in Psychology, 3(2), 77-101.

https://doi.org/10.1191/1478088706qp063oa

Braun, V., \& Clarke, V. (2012). Thematic analysis. In APA handbook of research methods in psychology, Vol 2: Research designs: Quantitative, qualitative, neuropsychological, and biological. (pp. 57-71). American Psychological Association. https://doi.org/10.1037/13620-004

Bueno, S., Gallego, M. D., \& Noyes, J. (2020). Uses and Gratifications on Augmented Reality Games: An Examination of Pokémon Go. Applied Sciences, 10(5), 1644. https://doi.org/10.3390/app10051644

Chen, H., Dai, Y., Meng, H., Chen, Y., \& Li, T. (2018). Understanding the Characteristics of Mobile Augmented Reality Applications. 2018 IEEE International Symposium on Performance Analysis of Systems and Software (ISPASS), 128-138. https://doi.org/10.1109/ISPASS.2018.00026

Civelek, I., Liu, Y., \& Marston, S. R. (2018). Design of Free-to-Play Mobile Games for the Competitive Marketplace. International Journal of Electronic Commerce, 22(2), 258288.

https://doi.org/10.1080/10864415.2018.14417 55

Di Sorbo, A., Panichella, S., Alexandru, C. V., Visaggio, C. A., \& Canfora, G. (2017). SURF: Summarizer of User Reviews Feedback. 2017 IEEE/ACM 39th International Conference on Software Engineering Companion (ICSE-C), 55-58. https://doi.org/10.1109/ICSE-C.2017.5

Etxeberria, A. I., Asensio, M., Vicent, N., \& Cuenca, J. M. (2012). Mobile devices: a tool for tourism and learning at archaeological sites. International Journal of Web Based Communities, 8(1), 57. https://doi.org/10.1504/IJWBC.2012.044682

Fagernäs, S., Hamilton, W., Espinoza, N., Miloff, A., Carlbring, P., \& Lindner, P. (2021). What do users think about Virtual Reality relaxation applications? A mixed methods study of online user reviews using natural language processing. Internet Interventions, 24, 100370. https://doi.org/10.1016/j.invent.2021.100370

Faric, N., Potts, H. W. W., Hon, A., Smith, L., Newby, K., Steptoe, A., \& Fisher, A. (2019). What Players of Virtual Reality Exercise Games Want: Thematic Analysis of WebBased Reviews. Journal of Medical Internet Research, 21(9), e13833. https://doi.org/10.2196/13833 
Frie, K., Hartmann-Boyce, J., Jebb, S., Albury, C., Nourse, R., \& Aveyard, P. (2017). Insights From Google Play Store User Reviews for the Development of Weight Loss Apps: MixedMethod Analysis. JMIR MHealth and UHealth, 5(12), e203.

https://doi.org/10.2196/mhealth.8791

Furió, D., Juan, M.-C., Seguí, I., \& Vivó, R. (2015). Mobile learning vs. traditional classroom lessons: a comparative study. Journal of Computer Assisted Learning, 31(3), 189-201. https://doi.org/10.1111/jcal.12071

Gao, C., Zeng, J., Lyu, M. R., \& King, I. (2018). Online app review analysis for identifying emerging issues. Proceedings of the 40th International Conference on Software Engineering, 48-58. https://doi.org/10.1145/3180155.3180218

Garcia, J. A., \& Navarro, K. F. (2014). The Mobile RehApp ${ }^{\text {TM}}$ : an AR-based mobile game for ankle sprain rehabilitation. 2014 IEEE 3nd International Conference on Serious Games and Applications for Health (SeGAH), 1-6. https://doi.org/10.1109/SeGAH.2014.7067087

Ghazwani, Y., \& Smith, S. (2020). Interaction in Augmented Reality. Proceedings of the 2020 4th International Conference on Virtual and Augmented Reality Simulations, 39-44. https://doi.org/10.1145/3385378.3385384

Guzman, E., \& Maalej, W. (2014). How Do Users Like This Feature? A Fine Grained Sentiment Analysis of App Reviews. 2014 IEEE 22nd International Requirements Engineering Conference (RE), 153-162. https://doi.org/10.1109/RE.2014.6912257

Hamari, J., Malik, A., Koski, J., \& Johri, A. (2019). Uses and Gratifications of Pokémon Go: Why do People Play Mobile Location-Based Augmented Reality Games? International Journal of Human-Computer Interaction, 35(9), 804-819.

https://doi.org/10.1080/10447318.2018.14971 15

Hoon, L., Vasa, R., Schneider, J.-G., \& Mouzakis, K. (2012). A preliminary analysis of vocabulary in mobile app user reviews. Proceedings of the 24th Australian ComputerHuman Interaction Conference on - $\mathrm{OzCHI}$ '12, 245-248. https://doi.org/10.1145/2414536.2414578

Hsiao, K.-L., Lytras, M. D., \& Chen, C.-C. (2019). An in-app purchase framework for locationbased AR games: the case of Pokémon Go. Library Hi Tech, 38(3), 638-653.

https://doi.org/10.1108/LHT-09-2018-0123

Huebner, J., Frey, R. M., Ammendola, C., Fleisch,
E., \& llic, A. (2018). What People Like in Mobile Finance Apps. Proceedings of the 17th International Conference on Mobile and Ubiquitous Multimedia, 293-304. https://doi.org/10.1145/3282894.3282895

lacob, C., \& Harrison, R. (2013). Retrieving and analyzing mobile apps feature requests from online reviews. 2013 10th Working Conference on Mining Software Repositories (MSR), 41-44. https://doi.org/10.1109/MSR.2013.6624001

Juan M, C., Furió, D., Alem, L., Ashworth, P., \& Cano, J. (2011). ARGreenet and BasicGreenet: Two mobile games for learning how to recycle. 19th International Conference in Central Europe on Computer Graphics, Visualization and Computer Vision, WSCG 2011 - In Co-Operation with EUROGRAPHICS, Full Papers Proceedings, 25-32.

Kang, S., Choi, H., Park, S., Park, C., Lee, J., Lee, U., \& Lee, S.-J. (2019). Fire in Your Hands: Understanding Thermal Behavior of Smartphones. The 25th Annual International Conference on Mobile Computing and Networking, 1-16. https://doi.org/10.1145/3300061.3300128

Karimi, S., \& Wang, F. (2017). Online review helpfulness: Impact of reviewer profile image. Decision Support Systems, 96, 39-48. https://doi.org/10.1016/j.dss.2017.02.001

Kesim, M., \& Ozarslan, Y. (2012). Augmented Reality in Education: Current Technologies and the Potential for Education. Procedia Social and Behavioral Sciences, 47, 297-302. https://doi.org/10.1016/j.sbspro.2012.06.654

Khalid, H., Shihab, E., Nagappan, M., \& Hassan, A. E. (2015). What Do Mobile App Users Complain About? IEEE Software, 32(3), 7077. https://doi.org/10.1109/MS.2014.50

Ko, S. M., Chang, W. S., \& Ji, Y. G. (2013). Usability Principles for Augmented Reality Applications in a Smartphone Environment. International Journal of Human-Computer Interaction, 29(8), 501-515. https://doi.org/10.1080/10447318.2012.72246 6

Koceski, S., \& Koceska, N. (2011). Interaction between players of mobile phone game with augmented reality (AR) interface. 2011 International Conference on User Science and Engineering (i-USEr ), 245-250. https://doi.org/10.1109/iUSEr.2011.6150574

Laine, T. (2018). Mobile Educational Augmented Reality Games: A Systematic Literature Review and Two Case Studies. Computers, 
$7(1), 19$.

https://doi.org/10.3390/computers7010019

Maalej, W., \& Nabil, H. (2015). Bug report, feature request, or simply praise? On automatically classifying app reviews. 2015 IEEE 23rd International Requirements Engineering Conference (RE), 116-125. https://doi.org/10.1109/RE.2015.7320414

Martin, W., Harman, M., Jia, Y., Sarro, F., \& Zhang, Y. (2015). The App Sampling Problem for App Store Mining. 2015 IEEE/ACM 12th Working Conference on Mining Software Repositories, 123-133.

https://doi.org/10.1109/MSR.2015.19

Mojica Ruiz, I. J., Nagappan, M., Adams, B., Berger, T., Dienst, S., \& Hassan, A. E. (2016). Examining the Rating System Used in MobileApp Stores. IEEE Software, 33(6), 86-92. https://doi.org/10.1109/MS.2015.56

Moro, C., Phelps, C., Redmond, P., \& Stromberga, Z. (2021). HoloLens and mobile augmented reality in medical and health science education: A randomised controlled trial. British Journal of Educational Technology, 52(2), 680-694. https://doi.org/10.1111/bjet.13049

Mulloni, A., Grubert, J., Seichter, H., Langlotz, T., Grasset, R., Reitmayr, G., \& Schmalstieg, D. (2012). Experiences with the Impact of Tracking Technology in Mobile Augmented Reality Evaluations. Proc. Mobile $\mathrm{HCl}$ Workshop on Mobile Vision and $\mathrm{HCl}$ (MobiVis) 2012, 2. http://data.icg.tugraz.at/ dieter/publications/S chmalstieg_237.pdf

Niantic - The Pokémon GO Team. (2016). 200,000 trips around the Earth! https://pokemongo.nianticlabs.com/post/milest ones/?hl=en

Nicholas, J., Fogarty, A. S., Boydell, K., \& Christensen, H. (2017). The Reviews Are in: A Qualitative Content Analysis of Consumer Perspectives on Apps for Bipolar Disorder. Journal of Medical Internet Research, 19(4), e105. https://doi.org/10.2196/jmir.7273

Oufqir, Z., El Abderrahmani, A., \& Satori, K. (2020). From Marker to Markerless in Augmented Reality (pp. 599-612). https://doi.org/10.1007/978-981-15-0947-6_57

Palmarini, R., Erkoyuncu, J. A., Roy, R., \& Torabmostaedi, H. (2018). A systematic review of augmented reality applications in maintenance. Robotics and ComputerIntegrated Manufacturing, 49, 215-228. https://doi.org/10.1016/j.rcim.2017.06.002

Panichella, S., Di Sorbo, A., Guzman, E., Visaggio,
C. A., Canfora, G., \& Gall, H. C. (2015). How can i improve my app? Classifying user reviews for software maintenance and evolution. 2015 IEEE International Conference on Software Maintenance and Evolution (ICSME), 281-290. https://doi.org/10.1109/ICSM.2015.7332474

Pyae, A., Mika, L., \& Smed, J. (2017). Understanding Players' Experiences in Location-based Augmented Reality Mobile Games. Extended Abstracts Publication of the Annual Symposium on Computer-Human Interaction in Play, 535-541. https://doi.org/10.1145/3130859.3131322

Pyae, A., \& Potter, L. E. (2016). A player engagement model for an augmented reality game. Proceedings of the 28th Australian Conference on Computer-Human Interaction $\mathrm{OzCHI}$ '16, 11-15.

https://doi.org/10.1145/3010915.3010960

Qian, J., Ma, J., Li, X., Attal, B., Lai, H., Tompkin, J., Hughes, J. F., \& Huang, J. (2019). Portalble: Intuitive Free-hand Manipulation in Unbounded Smartphone-based Augmented Reality. Proceedings of the 32nd Annual ACM Symposium on User Interface Software and Technology, 133-145. https://doi.org/10.1145/3332165.3347904

Qiao, X., Ren, P., Dustdar, S., Liu, L., Ma, H., \& Chen, J. (2019). Web AR: A Promising Future for Mobile Augmented Reality-State of the Art, Challenges, and Insights. Proceedings of the IEEE, 107(4), 651-666.

https://doi.org/10.1109/JPROC.2019.2895105

Radu, I., Guzdial, K., \& Avram, S. (2017). An Observational Coding Scheme for Detecting Children's Usability Problems in Augmented Reality. Proceedings of the 2017 Conference on Interaction Design and Children, 643-649. https://doi.org/10.1145/3078072.3084337

Rauschnabel, P. A., Rossmann, A., \& tom Dieck, M. C. (2017). An adoption framework for mobile augmented reality games: The case of Pokémon Go. Computers in Human Behavior, 76, 276-286.

https://doi.org/10.1016/j.chb.2017.07.030

Rodrigo, M. M. T., Caluya, N. R., Diy, W. D. A., \& Vidal, E. C. E. (2015). Igpaw: Intramuros Design of an augmented reality game for philippine history. Proceedings of the 23rd International Conference on Computers in Education, ICCE 2015, 489-498.

Sanna, A., \& Manuri, F. (2016). A Survey on Applications of Augmented Reality. Advances in Computer Science : An International Journal, 5(1), 18-27. http://www.acsij.org/acsij/article/view/400 
Saoane Thach, K., \& Phuong Nam Phan, T. (2019).

Persuasive Design Principles in Mental Health Apps: A Qualitative Analysis of User Reviews. 2019 IEEE-RIVF International Conference on Computing and Communication Technologies (RIVF), 1-6. https://doi.org/10.1109/RIVF.2019.8713753

Tan, M. L., Prasanna, R., Stock, K., Doyle, E. E. H., Leonard, G., \& Johnston, D. (2020). Modified Usability Framework for Disaster Apps: A Qualitative Thematic Analysis of User Reviews. International Journal of Disaster Risk Science, 11(5), 615-629. https://doi.org/10.1007/s13753-020-00282-x

Terry, G., Hayfield, N., Clarke, V., \& Braun, V. (2017). Thematic Analysis. In The SAGE Handbook of Qualitative Research in Psychology (pp. 17-36). SAGE Publications Ltd. https://doi.org/10.4135/9781526405555.n2

Thach, K. S. (2018). User's perception on mental health applications: a qualitative analysis of user reviews. 2018 5th NAFOSTED Conference on Information and Computer Science (NICS), 47-52. https://doi.org/10.1109/NICS.2018.8606901

Tuli, N., \& Mantri, A. (2020). Usability Principles for Augmented Reality based Kindergarten Applications. Procedia Computer Science, 172, 679-687. https://doi.org/10.1016/j.procs.2020.05.089

Vaismoradi, M., Turunen, H., \& Bondas, T. (2013). Content analysis and thematic analysis: Implications for conducting a qualitative descriptive study. Nursing \& Health Sciences, 15(3), 398-405.

https://doi.org/10.1111/nhs. 12048

Vasa, R., Hoon, L., Mouzakis, K., \& Noguchi, A. (2012). A preliminary analysis of mobile app user reviews. Proceedings of the 24th Australian Computer-Human Interaction Conference on - OzCHI '12, 241-244. https://doi.org/10.1145/2414536.2414577

Wetzel, R., Blum, L., Broll, W., \& Oppermann, L. (2011). Designing Mobile Augmented Reality Games. In B. Furht (Ed.), Handbook of Augmented Reality (pp. 513-539). Springer New York. https://doi.org/10.1007/978-14614-0064-6_25

Zarzuela, M. M., Pernas, F. J. D., Martínez, L. B., Ortega, D. G., \& Rodríguez, M. A. (2013). Mobile Serious Game Using Augmented Reality for Supporting Children's Learning About Animals. Procedia Computer Science, 25, 375-381.

https://doi.org/10.1016/j.procs.2013.11.046
Zsila, Á., Orosz, G., Bőthe, B., Tóth-Király, I., Király, O., Griffiths, M., \& Demetrovics, Z. (2018). An empirical study on the motivations underlying augmented reality games: The case of Pokémon Go during and after Pokémon fever. Personality and Individual Differences, 133, 56-66. https://doi.org/10.1016/j.paid.2017.06.024 